\title{
Electrical Transport in Copper and Cobalt Ferricyanides
}

\author{
K. Tennakone \\ Department of Physics, Ruhuna University College, Matara, Sri Lanka \\ (Date of receipt: 09 August 1983) \\ (Date of acceptance: 30 March 1984)
}

\begin{abstract}
Copper and cobalt ferricyanides are found to be electrical conductors. The temperature variation of their resistivities are studied. It is found that the activation energy of copper ferricyanide is $0.23 \mathrm{eV}$ provided the sample is not heated above $118^{\circ} \mathrm{C}$. If the sample is heated above $118^{\circ} \mathrm{C}$ a partial chemical degradation of the compound transforms the activation energy to $1.43 \mathrm{eV}$. Cobalt ferricyanide has exactly similax behaviour, the activation energy changes from $0.25 \mathrm{eV}$ to $0.61 \mathrm{eV}$ if the sample is heated above $132^{\circ} \mathrm{C}$.
\end{abstract}

The ferricyanides and ferrocyanides of most heavy metals are water insoluble stable crystalline solids having similar structure. ${ }^{1},{ }^{7}$ We have found that a number of ferricyanides and ferrocyanides of heavy metals conduct electricity. ${ }^{5}$ In this note we report the electrical conduction properties of copper ferricyanides $\left(\mathrm{CO}_{3}\left(\mathrm{Fe}(\mathrm{CN})_{6}\right)_{2}\right.$ and cobalt ferricyanides $\left(\mathrm{Co}_{3}\left(\mathrm{Fe}(\mathrm{CN})_{6}\right)_{2}\right)$. These two compounds were selected because they have identical structures with similar lattice parameters.

Copper ferricyanide is prepared by mixing aqueous solutions of copper sulphate and potassium ferricyanide (analytical grade reagents are used without further purification). The precipitate of copper ferricyanide is washed with de-ionized water and dried at $70^{\circ} \mathrm{C}$. The ycllowish green polycrystalline powder of copper ferricyanide contains 14 molecules of water of crystallization. If the drying temperature is raised (e.g. $90^{\circ} \mathrm{C}$ ) the water of crystallization is lost but traces of absorbed moisture remain in the crystals. The cobalt ferricyanide prepared in the same manner by mixing aqueous solutions of potassium ferricyanide and cobalt nitrate is a brick red polycrystalline powder containing no water of crystallization.

To measure the resistivity, the powder (dried at $90^{\circ} \mathrm{C}$ ) is compacted into a glass tube (diameter $0.8 \mathrm{~cm}$ ) and pressed between carbon electrodes to a pressure of $10^{8} \mathrm{~Pa}$ when a pellet (length $0.5 \mathrm{~cm}$ ) is formed. The ends of the tube are sealed with epoxy resin, the samples are immersed in a thermostatic oil bath and the d.c. resistance at different temperatures is measured using a digital bridge type resistance meter. The temperature variation of the resistivity of copper and cobalt ferricyanides is indicated in Figures 1 and 2 . In both cases the plot of $\log p$ vs $T-1$ fits into two straight line portions indicating that the resistivity changes with temperature according to the law,

$$
p=p_{0} e^{E / K T}
$$




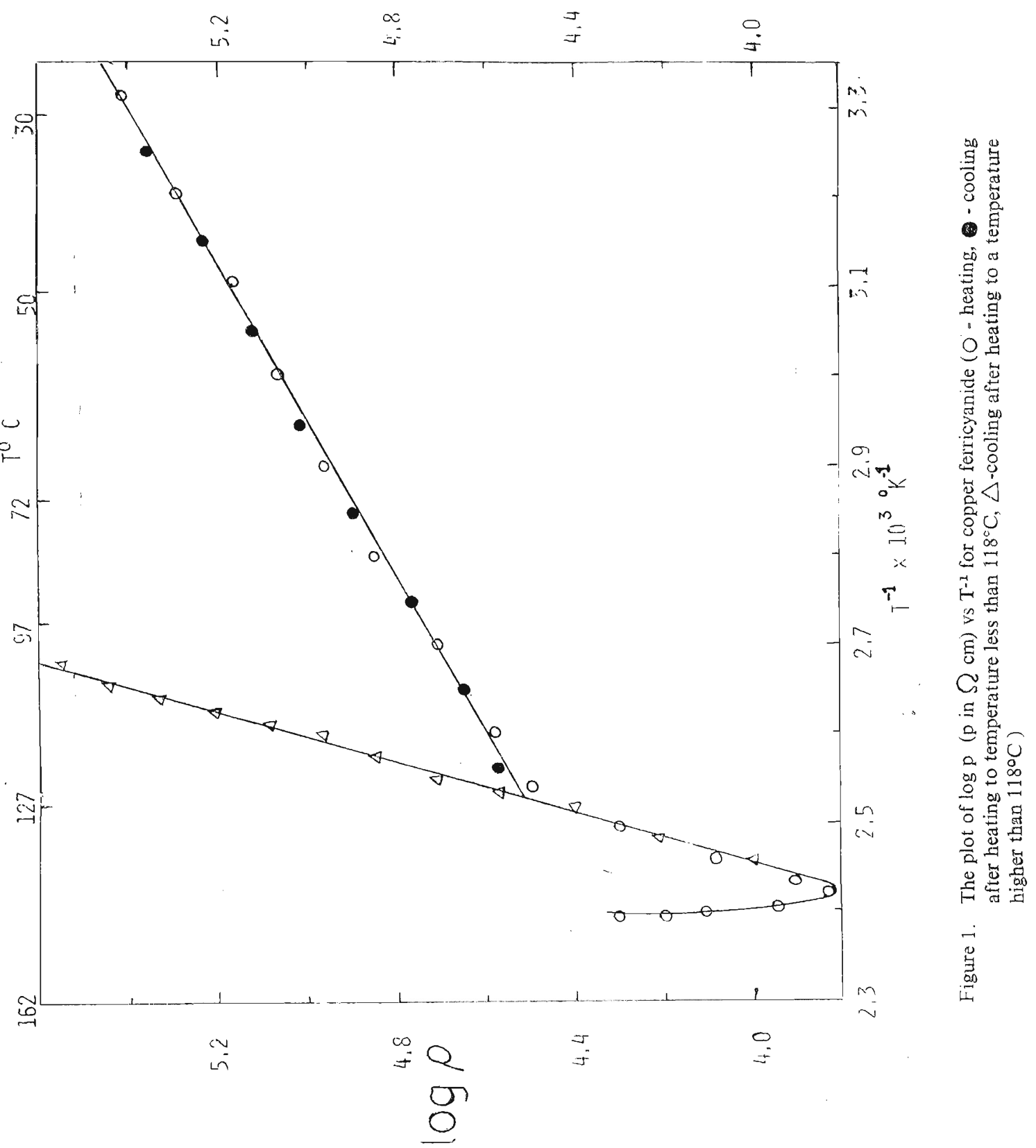




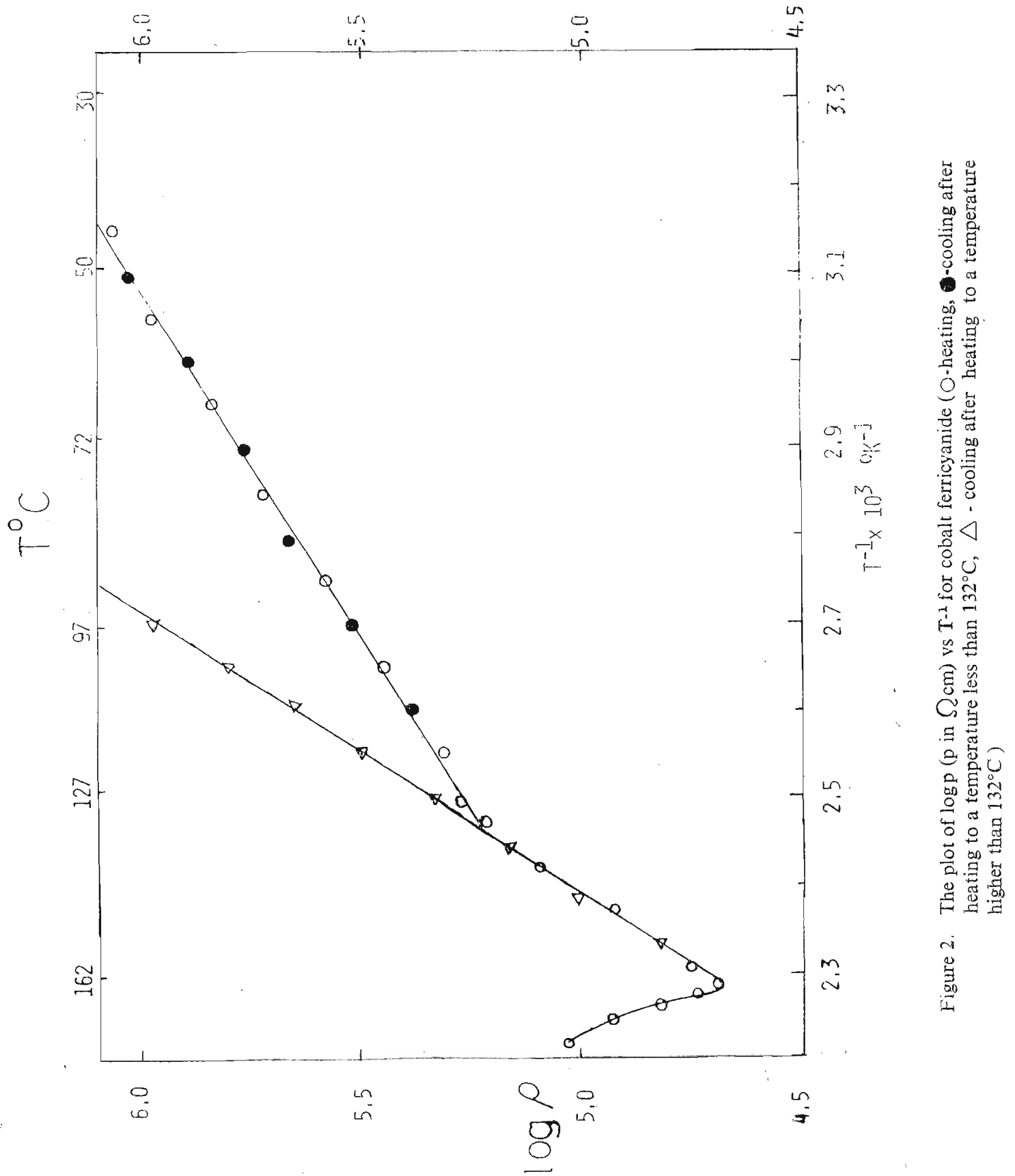


In copper ferricyanide the activation energy is $E=0.23 \mathrm{eV}$ and $p_{0}=43 \Omega \mathrm{cm}$ up to a temperature of $118^{\circ} \mathrm{C}$. At $118^{\circ} \mathrm{C}$ a transition takes place and in the temperature range $118-138^{\circ} \mathrm{C}, \mathrm{E}$ and $\mathrm{p}_{0}$ takes the value $1.43 \mathrm{eV}$ and $2 \times 10^{-14} \Omega \mathrm{cm}$ respectively. If the sample is allowed to cool before it had reached $118^{\circ} \mathrm{C}$, the temperature variation of resistivity follows the same path as on heating. However, if the sample is allowed to cool once $\mathrm{T}$ has exceeded $118^{\circ} \mathrm{C}$, the second path, i.e. one corresponding to $E=1.43 \mathrm{eV}$ and $p_{0}=2 \times 10^{-14} \Omega \mathrm{cm}$ is followed at all temperatures (Figure 1). The transition at $118^{\circ} \mathrm{C}$ seems to be due to a partial degradation of the compound.

The related compound cobalt ferricyanide shows an exactly similar behaviour The plot of $\log \mathrm{p}$ vs $\mathrm{T}_{-1}{ }^{1}$ has two straight line portions with $E=0.25 \mathrm{eV}, p_{\mathrm{s}}=1.4 \times$ $10^{2} \Omega \mathrm{cm}$ and $E=0.67 \mathrm{eV}, p_{0}=4.2 \times 10-3 \Omega \mathrm{cm}$. The transition temperature in this case is $132^{\circ} \mathrm{C}$. Until a temperature of $132^{\circ} \mathrm{C}$ is reached, the resistivity varies as in (1) with $E=0.25 \mathrm{eV}$ and $p=4.2 \times 10^{2} \Omega \mathrm{cm}$. If the sample is allowed to cool before the transition temperature, $p$ varies along the same path, which it had followed during heating. However, if the sample is heated beyond the transition temperature of $132^{\circ} \mathrm{C}$, the resistivity changes along the second path (i.e. one corresponding to $E=0.61 \mathrm{eV}, p_{0}=4.2 \times 10^{-3} \Omega \mathrm{cm}$ upon cooling). The transition here again is probably due to partial degradation of the compound.

Heavy metal ferricyanides generally undergo thermal decomposition into carbon, metallic carbides and cyanogen. ${ }^{6}$ The decomposition temperature of copper and cobalt ferricyanides are respectively $138^{\circ} \mathrm{C}$ and $163.7^{\circ} \mathrm{C}$. Carbon and metallic carbides can be identified in the decomposition products. However, it is possible that partial decomposition occurs at much lower temperatures. Even minute quantities of degradation products introduced as impurities into the lattice drastically change the conductivity characteristics.

The observed temperature variation of the resistivity 3 of copper and cobalt ferricyanides suggest that in both these substances the conductivity is electronic (electrons or holes). When large direct currents are passed through this layers of these materials for long intervals of time, no changes in conductivity characteristics are observed, indicating that ionic conduction ${ }^{3}{ }^{4}$ is negligible or absent (this remains true even when the transition temperature is exceeded). The details of the crystal structure of copper and cobalt ferricyanides is not reported in literature to the knowledge of the authors. However, the crystal structure of several ferrocyanides and the Prussian blue group of ferricyanides is well studied. ${ }^{1}{ }^{7}$ All these substances have similar cubic structures with face centred arrangement of $\mathrm{Fe}(\mathrm{CN})_{0}$ groups. ${ }^{1, "}$ 


\section{References}

1. AyERs, J. B. \& WAGGONER, W. H. (1971). J. inorg. nucl. Chem 33: 721.

2. Hradik, J. (1972). (ed), Physics of Electrolytes, 1, Academic press, New York.

3. Kittel, C. (1965). Introduction to solid state Physics John Wiley New York.

4. Makan, G. D. \& Roth, W. I. (1976). Superionic Conductors, Plenum, New York.

5. Tennakone, K. \& Kaluarachch, D. (1980). Phys. Stat. Sol. (a) 58; K55.

6. Vogel, A. I. (1979). Textbook of Macro and Semimicro qualitative Inorganic Analysis, 5th ed. Longman, London.

7. Wriger, H. B., Millugan, W. O. \& Bates, J. B. (1942), J. Physical Chem. 46: 99. 